\title{
Potential of Partially Superconducting Generators for Large Direct-Drive Wind
} Turbines

\author{
Liu, Dong; Polinder, Henk; Abrahamsen, Asger Bech; Ferreira, Jan Abraham
}

Published in:

I E E E Transactions on Applied Superconductivity

Link to article, DOI:

10.1109/TASC.2017.2707661

Publication date:

2017

Document Version

Peer reviewed version

Link back to DTU Orbit

Citation (APA):

Liu, D., Polinder, H., Abrahamsen, A. B., \& Ferreira, J. A. (2017). Potential of Partially Superconducting Generators for Large Direct-Drive Wind Turbines. I E E E Transactions on Applied Superconductivity, 27(5), [5203711]. https://doi.org/10.1109/TASC.2017.2707661

\section{General rights}

Copyright and moral rights for the publications made accessible in the public portal are retained by the authors and/or other copyright owners and it is a condition of accessing publications that users recognise and abide by the legal requirements associated with these rights.

- Users may download and print one copy of any publication from the public portal for the purpose of private study or research.

- You may not further distribute the material or use it for any profit-making activity or commercial gain

- You may freely distribute the URL identifying the publication in the public portal 
Delft University of Technology

\section{Potential of Partially Superconducting Generators for Large Direct-Drive Wind Turbines}

Liu, Dong; Polinder, Henk; Abrahamsen, Asger B.; Ferreira, Bram

DOI

10.1109/TASC.2017.2707661

Publication date

2017

Document Version

Peer reviewed version

Published in

IEEE Transactions on Applied Superconductivity

\section{Citation (APA)}

Liu, D., Polinder, H., Abrahamsen, A. B., \& Ferreira, J. A. (2017). Potential of Partially Superconducting Generators for Large Direct-Drive Wind Turbines. IEEE Transactions on Applied Superconductivity, 27(5), 1-11. [5203711]. DOI: 10.1109/TASC.2017.2707661

\section{Important note}

To cite this publication, please use the final published version (if applicable).

Please check the document version above.

\section{Copyright}

Other than for strictly personal use, it is not permitted to download, forward or distribute the text or part of it, without the consent of the author(s) and/or copyright holder(s), unless the work is under an open content license such as Creative Commons. 


\title{
Potential of Partially Superconducting Generators for Large Direct-Drive Wind Turbines
}

\author{
Dong Liu, Student Member, IEEE, Henk Polinder, Senior Member, IEEE, \\ Asger B. Abrahamsen, Member, IEEE, and Jan A. Ferreira, Fellow, IEEE
}

\begin{abstract}
This paper aims at assessing the potential of partially superconducting generators for $10 \mathrm{MW}$ direct-drive wind turbines by investigating their performance for a very wide range of excitation currents. Performance indicators such as shear stress and efficiency and other generator characteristics are compared for twelve different generator topologies. To be sufficiently attractive, superconducting generators must have significant advantages over permanent magnet direct drive generators which typically have shear stresses in the order of $53 \mathrm{kPa}$ and efficiencies of $96 \%$. Therefore, it is investigated what excitation is required to obtain a doubled shear stress and an efficiency of $98 \%$. To achieve this, the different topologies require a range of excitation from 200 to $550 \mathrm{kAt}$ (Ampere-turns) with a low armature current density of $2 \mathrm{~A} / \mathrm{mm}^{2}$. The more iron is used in the core of these topologies, the easier they achieve this performance. By examining the maximum magnetic flux density at the location of the superconducting field winding, feasible superconductors can be chosen according to their engineering current density capabilities. It is found that high- and low temperature superconductors can meet the performance criteria for many of the topologies. $\mathbf{M g B}_{2}$ superconductors are feasible for the fully iron-cored topology with salient poles but needs cooling down to $10 \mathrm{~K}$.
\end{abstract}

Index Terms-Direct drive, HTS, LTS, $\mathrm{MgB}_{2}$, performance, potential, superconducting generator, wind turbine.

\section{INTRODUCTION}

$\mathbf{S}$ UPERCONDUCTING synchronous generators are being proposed and designed for large direct-drive wind power conversion (10-20 MW) [1], because of their low weight and compactness [2]-[4]. A commonly applied approach is to use superconducting (SC) wires with high current carrying capability in the DC field winding, whereas copper conductors remain in the AC armature winding [5]-[8]. Such so-called partially SC generators can be designed based on the properties of currently available SC materials. However, the designs proposed in the literature have been facing various challenges, such as large amounts of costly SC materials [9], [10], low efficiencies [9]-[13], large diameters [11], [12] or large active material weights [13].

These designs partly or entirely use iron cores, which tend to increase the generator weight [10]-[14]. Large air gap diameters with more poles can be adopted to reduce the weight [11], [12]. However, this approach increases the generator and nacelle sizes and challenges the mechanical

D. Liu, H. Polinder, and J. A. Ferreira are with the Department of Electrical Sustainable Energy, Delft University of Technology, NL-2628 CD Delft, Netherlands. E-mail: d.liu-1@tudelft.nl.

A. B. Abrahamsen is with DTU Wind Energy, Technical University of Denmark, DK-4000 Roskilde, Denmark. construction [15]. To reduce the diameter, higher electrical loadings may be used but the results are higher copper losses and lower efficiencies [11], [12].

An SC generator has a much wider range of field excitation than permanent magnet and copper-field-winding generators. Moreover, the superconductor technology is developing rapidly. Thus, it does not make sense to base SC generator designs only on the properties of currently available superconductors. It is therefore interesting to evaluate the potential performance of an SC generator by disregarding the superconductor type, eliminating the limitation of critical characteristics and increasing the current density capability of the superconductors. We can then find out the required superconductor types that meet the magnetic field level and required current density for achieving certain high generator performance.

The objective of this paper is to find the potential of partially SC generators. Such generators can only be attractive if they have significant advantages over permanent magnet direct drive (PMDD) generators. Typically, a PMDD generator has shear stresses in the order of $53 \mathrm{kPa}$ and efficiencies of $96 \%$. Therefore, it is investigated what excitation is required to obtain a doubled shear stress of $106 \mathrm{kPa}$ and an efficiency of $98 \%$. Other generator characteristics, such as normal stress, stack length and active material mass, are also investigated to show the effects of increasing the excitation. Commercial superconductors, i.e. low- and high-temperature superconductors and $\mathrm{MgB}_{2}$ superconductors are evaluated to meet the magnetic field and field current density resulted from the required excitation.

\section{Generator to Be Studied}

\section{A. General Specifications}

The partially SC generator for this study is proposed for a 10 MW direct-drive offshore wind turbine with a foundation for the water depth of $50 \mathrm{~m}$ as investigated in the INNWIND.EU project [1]. The rated speed is $9.6 \mathrm{rpm}$, and the rated torque is therefore $10 \mathrm{MN} \cdot \mathrm{m}$.

\section{B. Twelve Topologies}

Iron and non-magnetic cores can both be used in an SC machine. Using iron cores is more conventional and can reduce the magnetic reluctance of a machine and the amount of used superconductors. The downsides are large weights and extra iron losses. Non-magnetic cores can be applied to SC machines because the magnetic field excited by SC field 


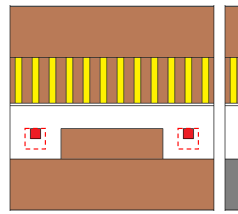

(a) $\mathrm{T} 1$

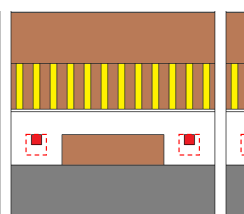

(b) $\mathrm{T} 2$

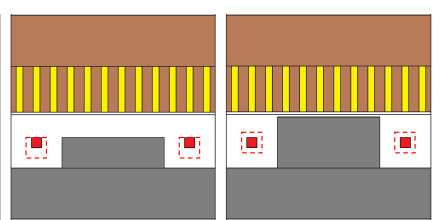

(c) $\mathrm{T} 3$

(d) $\mathrm{T} 4$

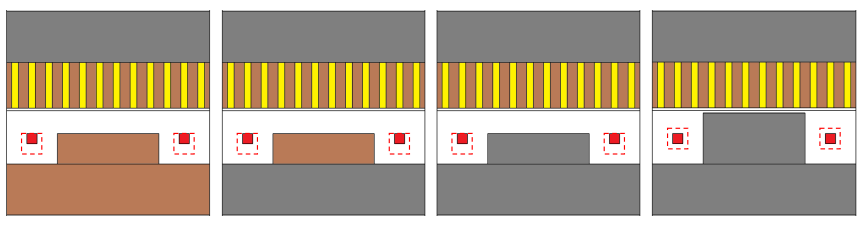

(e) $\mathrm{T} 5$

(f) $\mathrm{T} 6$

(g) $\mathrm{T} 7$

(h) $\mathrm{T} 8$

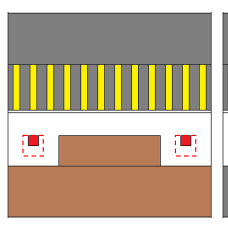

(i) $\mathrm{T} 9$

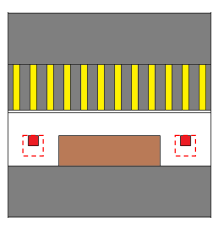

(j) $\mathrm{T} 10$

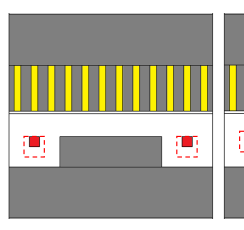

(k) $\mathrm{T} 11$

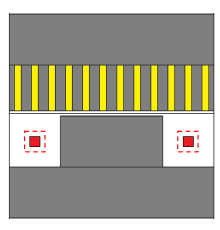

(1) $\mathrm{T} 12$
Fig. 1. Twelve topologies to be compared. Red: SC field winding. Yellow: copper armature winding. Brown: non-magnetic core. Gray: iron core. The dashed boxes are the contours for a larger coil.

windings can be very high. Usually non-magnetic cores are lightweight and loss free, but the magnetic reluctance of a machine would be so large that more superconductors have to be used to produce a sufficiently high magnetic field.

Combining iron and non-magnetic cores in the rotor back core, rotor pole core, stator tooth and stator yoke results in twelve applicable topologies (T1-T12) in total as listed and illustrated in Fig. 1. In this list, nine topologies T1-T3, T5T7, and T9-T11 have a large effective air gap length due to space allocated to the cryostat wall and thermal insulation. The other three topologies T4, T8 and T12 with salient poles have a significantly reduced effective air gap length. T4, T8 and T12 can be regarded as the extensions of T3, T7 and T11, respectively, from the topology point of view. In these three topologies, the cryostat can be made modular in the shape of racetrack so that the iron pole can go much closer to the stator [11]-[13], [16].

\section{Dimensioning}

One pole of the SC generator is dimensioned as illustrated in Fig. 2. Then this single pole can be applied to different generator diameters. The size of the generator is then determined by the number of poles according to specific requirements.

The basic generator design and pole dimensioning are rough but generalized for all the topologies. The design parameters are set to achieve realistic designs although they may affect each topology a bit differently. Since the purpose of topology comparison is to show trends with the excitation currents and then no optimization is involved, the basic design which provides the same conditions is considered acceptable for performance comparison.

The pole pitch is set to $\tau_{p}=0.4 \mathrm{~m}$ and three reasons support this choice:

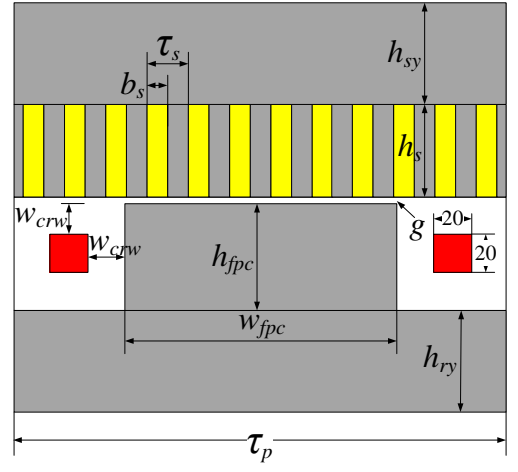

Fig. 2. Sketch of dimensioning parameters of one pole.

- According to the design proposals available in the literature, pole pitches between $0.379 \mathrm{~m} \mathrm{[10]} \mathrm{and} 0.660 \mathrm{~m} \mathrm{[12]} \mathrm{are}$ all possible.

- A previous optimization study for a low cost has shown that the pole pitch lies between $0.4 \mathrm{~m}$ and $0.7 \mathrm{~m}$ for different topologies [14]. The generator design resulting in the lowest cost has a small pole pitch about $0.4 \mathrm{~m}$.

- The pole pitch should be larger than the minimum bending diameter of the superconductor which differs from type to type. It is thus not allowed to wind an SC field coil with a very small pole pitch.

The mechanical air gap length of the machine is $g=10 \mathrm{~mm}$ which is roughly around $0.1 \%$ of possible air gap diameters. In the rotor, the pole core width is assumed to be $w_{f p c}=0.5 \tau_{p}=$ $0.2 \mathrm{~m}$. The heights of the rotor back core and the stator yoke are thus equally set to $h_{r y}=h_{s y}=0.5 w_{f p c}=0.1 \mathrm{~m}$. The pole core height is $h_{f p c}=60 \mathrm{~mm}$ for topologies T1-T3, T5-T7 and T9-T11, and $h_{f p c}=100 \mathrm{~mm}$ for topologies T4, T8 and T12 (the difference of $40 \mathrm{~mm}$ is due to the extension of the pole core). The cryostat wall thickness with thermal insulations occupies $w_{c r w}=40 \mathrm{~mm}$, which makes the effective air gap length of T1-T3, T5-T7 and T9-T11 become $g_{\text {eff }}=g+w_{c r w}=$ $50 \mathrm{~mm}$.

In the stator, the number of phases is $m=3$. The number of slots per pole per phase is $q=4$. The ratio of slot width to slot pitch is $b_{s} / \tau_{s}=0.5$ (an equal fraction for a slot and a tooth). The slot height of $h_{s}=84 \mathrm{~mm}$ is determined for achieving an electrical loading of $75 \mathrm{kA} / \mathrm{m}$ for forcedair cooling [17], with the rated current density in the stator winding being $J_{s}=3 \mathrm{~A} / \mathrm{mm}^{2}$ (RMS value). The armature current density of $J_{s}=3 \mathrm{~A} / \mathrm{mm}^{2}$ is usually a starting point for designing a large electrical machine [18]. Many designs of SC generators for wind turbines in the literature have used this current density or slightly lower [9]-[13]. However, the efficiency of these designs may not be high. A lower current density could be used to improve the efficiency. Therefore, this study will also investigate $J_{s}=2 \mathrm{~A} / \mathrm{mm}^{2}$ and compare it with $J_{s}=3 \mathrm{~A} / \mathrm{mm}^{2}$. Accordingly, the slot height is adjusted to $h_{s}=126 \mathrm{~mm}$ for $J_{s}=2 \mathrm{~A} / \mathrm{mm}^{2}$ to maintain the electrical loading of $75 \mathrm{kA} / \mathrm{m}$.

The excitation or excitation current $N I$ is calculated by the current density $J_{f}$ multiplied by the cross-sectional area of the field coil $A_{f}$. In this paper, the cross-sectional dimension of 


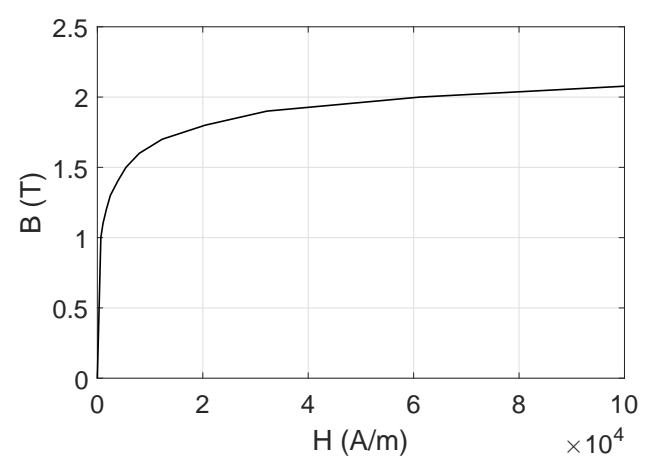

Fig. 3. B-H curve (silicon steel NGO M-14) used in the FE simulations. Reproduced from COMSOL Multiphysics v4.4.

one side of an SC field coil is fixed to $20 \mathrm{~mm}$ by $20 \mathrm{~mm}$. As a result, the excitation is only determined by the current density applied in the SC field winding. However, only the excitation, which is equal to the area of $A_{f}=400 \mathrm{~mm}^{2}$ multiplied by the current density $J_{f}$, takes effect for calculating the performance indicators and generator characteristics. Therefore, we do not need to know specifically either the current density or area until the feasibility of superconductors is evaluated, which will be presented in Section VI.

\section{Modeling Methods and Generator Operation}

The performance indicators and generator characteristics are modeled and calculated regarding their relation with the excitation current for the twelve topologies. 2D finite element (FE) models have to be used to calculate the magnetic field because this study involves the linear low field region, the non-linear medium field region and the linear high field region of the B-H curve of iron (Fig. 3). Then these quantities are calculated with analytical equations.

For calculating all these quantities, the generator is operated in such a way that the armature magnetic field is perpendicular to the excitation field. In the $d-q$ reference frame, this operation corresponds to the zero $d$-axis current control.

\section{PERFORMANCE INDICATORS}

The shear stress and efficiency (or total loss) are performance indicators for assessing a generator.

\section{A. Shear Stress}

The shear stress $\sigma_{t}$ is used for sizing an electrical machine by

$$
T_{e}=\frac{\pi}{2} \sigma_{t} D_{s}^{2} L_{s}
$$

where $T_{e}$ is the electromagnetic torque, $D_{s}$ is the air gap diameter, and $L_{s}$ is the stack length. The shear stress needs to be calculated first of all. In 2D FE models, the shear force per unit length on one pole $F_{t}$ is calculated with the Maxwell stress tensor by

$$
F_{t}=\frac{1}{\mu_{0}} \int_{l_{1}=0}^{l_{2}=\tau_{p}} B_{r} B_{t} d l
$$

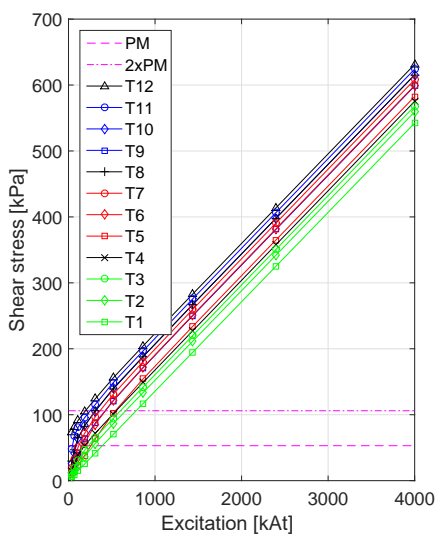

(a) Full range

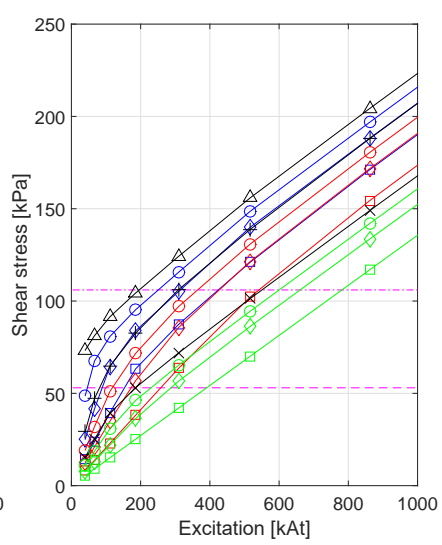

(b) Zoom in (low excitation)
Fig. 4. Shear stress with respect to excitation currents of the topologies T1-12. Dashed horizontal lines indicate the typical shear stress of a PMDD generator (lower) and twice the PMDD generator level (upper).

where $\tau_{p}$ is the pole pitch, and $B_{r}$ and $B_{t}$ are the radial and tangential components of the air gap flux density.

The shear force $F_{t}$ is an average value calculated from two stationary FE simulations. These two simulations differ in the relative position between the rotor and stator, and the phase angle of the armature current. From the first position to the second, the rotor rotates with an angle of $1 /(4 m q)$ of a mechanical cycle while the phase current shifts by a time of $1 /(4 m)$ of an electrical cycle. Choosing these two positions is under the assumption that the $6_{t h}$ time harmonic of the magnetic field contributes to the force ripples most. Then, an electrical cycle has 6 cycles of force ripples. Compared with a complete transient simulation of the shear force, the error resulted from this averaging method is less than 3\%. Since the aim of this study is just to find trends, this accuracy is acceptable.

Then the shear stress $\sigma_{t}$ is obtained by averaging $F_{t}$ over the pole pitch $\tau_{p}$ :

$$
\sigma_{t}=\frac{F_{t}}{\tau_{p}}
$$

The effects of excitation currents on the shear stress of the twelve topologies are shown in Fig. 4. At low excitation, the shear stress increases fast when the excitation increases. Saturation starts to play a role with a higher excitation and the increase of shear stress becomes slow. Finally, the relative permeability of iron becomes $\mu_{r} \approx 1$ with a significantly high excitation, and the shear stress varies linearly.

The twelve topologies, in general, follow the trend: the shear stress becomes higher from T1 to T12. With a very high excitation, the shear stress of all the topologies finally becomes parallel with each other. This result implies that using iron cores can effectively increase the shear stress even though it is saturated.

The typical shear stress of a PMDD generator is about $53 \mathrm{kPa}$ which is also plotted in Fig. 4. This number is estimated by considering an air gap magnetic field of $1 \mathrm{~T}$ (amplitude) and an electrical loading of $75 \mathrm{kA} / \mathrm{m}$ (RMS). If we want to achieve a doubled shear stress, i.e. $106 \mathrm{kPa}$, as indicated in 
Fig. 4, the excitation must be sufficiently high. However, the difficulty in reaching $106 \mathrm{kPa}$ is quite different for the twelve topologies. The topologies with more iron show higher shear stresses than the others. The topology T12 achieves $106 \mathrm{kPa}$ much more easily than T1. For $106 \mathrm{kPa}, \mathrm{T} 12$ requires the excitation of $200 \mathrm{kAt}$ while T1 requires $800 \mathrm{kAt}$. The other topologies lie in between.

\section{B. Efficiency at Rated Load (Simplified Loss Model)}

An efficiency is actually dependent on the torque, speed and machine size. However, calculation of efficiency can be simplified if armature copper Joule losses are dominant and other losses, such as iron losses and copper eddy current losses, are neglected. Such simplification can facilitate basic observation of how efficiency is related to the key variables.

The total loss primarily comes from the copper loss in the armature winding and the core loss in the iron, if the cooling power consumption is not taken into account. The copper loss consists of Joule losses and eddy current losses. For the purpose of making an efficiency independent of the power rating, the iron loss can be assumed to be negligible due to the low frequency of the direct-drive generator. The copper eddy current loss can also be assumed to be negligible by assuming very fine stranding of copper filaments. Therefore, only the Joule loss is left in efficiency calculation. Then the efficiency $\eta$ can be calculated by:

$$
\eta=1-\frac{C \cdot J_{s}^{2}\left(1+\frac{L_{e w}}{L_{s}}\right)}{\sigma_{t} v}
$$

where $L_{e w}$ is the length of one end of an armature winding turn, $L_{s}$ is the stack length, $J_{s}$ is the RMS current density in the armature winding, $\sigma_{t}$ is the shear stress calculated from Eq. (3), and $v$ is the relative linear speed between the generator rotor and stator. The constant $C$ is defined as

$$
C=\rho_{C u} h_{s} k_{f i l}\left(\frac{b_{s}}{\tau_{s}}\right)
$$

where $\rho_{C u}$ is the resistivity of copper, $k_{f i l}$ is the fill factor of the armature slots, and $h_{s}, b_{s}$ and $\tau_{s}$ have been defined in Section II-C. From Eq. (4), it is clear that the efficiency can be increased by reducing the armature current density $J_{s}$ or the ratio of end winding length to stack length $L_{e w} / L_{s}$, or by increasing the linear speed $v$.

The efficiencies at rated load with an armature current density of $J_{s}=3 \mathrm{~A} / \mathrm{mm}^{2}$ are plotted in Figs. 5, assuming the end winding length is much smaller than the stack length whereby the term $L_{e w} / L_{s}$ is neglected in Eq. (4). The topologies T1 and T12 are shown as two extreme cases (fully nonmagnetic compared with fully iron-cored with salient poles). In Fig. 5, T12 is much more efficient than T1 in the excitation region lower than e.g. $1000 \mathrm{kAt}$. With a higher excitation, the differences become small. This result matches the comparison of shear stress $\sigma_{t}$ in Fig. 4 since T12 has much higher shear stresses than $\mathrm{T} 1$. This result also implies that using more iron cores can effectively increase the generator efficiency, especially when the excitation is limited.

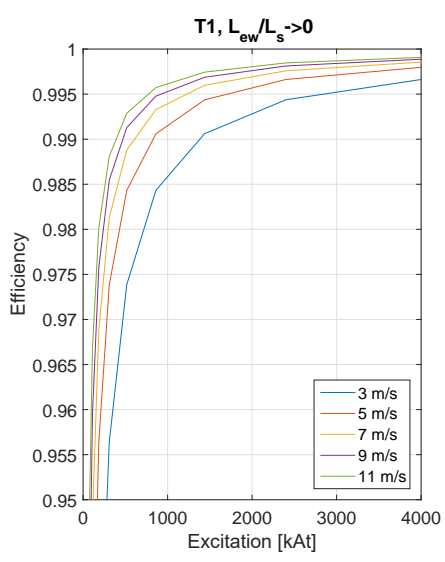

(a) $\mathrm{T} 1$

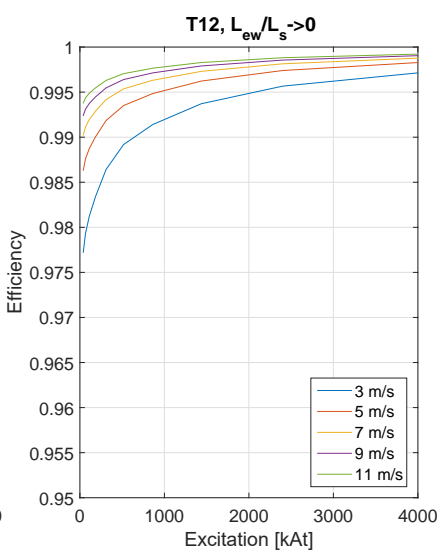

(b) $\mathrm{T} 12$
Fig. 5. Efficiency of topologies $\mathrm{T} 1$ and $\mathrm{T} 12$ with $J_{s}=3 \mathrm{~A} / \mathrm{mm}^{2}$, when only armature copper Joule losses are considered and $L_{e w} / L_{s} \rightarrow 0$ is assumed in Eq. (4).

\section{Losses at Rated Load (Detailed Loss Model)}

For calculating all the losses, we use the rated torque of $T_{e}=10 \mathrm{MN} \cdot \mathrm{m}$ and the rated angular speed of $n_{N}=9.6 \mathrm{rpm}$. Three air gap diameters $D_{s}=6.11 \mathrm{~m}, 10.19 \mathrm{~m}$ and $14.26 \mathrm{~m}$ are compared which cover the range of commonly applied diameters proposed in the literature. These diameters contain 48, 80 and 112 poles, respectively, as a result of the fixed pole pitch of $\tau_{p}=0.4 \mathrm{~m}$ defined in Section II-C.

Three types of losses are usually considered and calculated in an electrical machine:

- Copper Joule loss ( $\mathrm{I}^{2} \mathrm{R}$ loss)

- Copper eddy current loss

- Iron loss

In Section III-B, the first loss has been calculated and the latter two losses were neglected, because the power rating and the generator size were both assumed unknown. In this section, we have set a rated power and three air gap diameters so we can then calculate all these three losses.

A few assumptions are made for calculating these losses:

- Iron will saturate when the excitation becomes high. Under heavy saturation, the hysteresis loop can be illustrated in Fig. 6. We may increase the excitation to such a high level that iron is fully saturated. Thus, the most important assumption for iron losses is that the relative permeability of iron becomes $\mu_{r}=1$ after the magnetic flux density is over a particular value. Here we assume this value to be $B_{h y s}=2.5 \mathrm{~T}$. This assumption also implies that the area of the hysteresis loop reaches its maximum at $B_{h y s}=2.5 \mathrm{~T}$ at point $\mathrm{U}$ (also point $X)$. With a higher magnetic field, the area of the hysteresis loop will not expand anymore.

- The copper eddy current loss is calculated only in the stack length without the end winding. This allows for 2D analyses with an acceptable accuracy. For calculating the copper Joule loss, the end winding is included.

- The rotor iron is assumed to be loss free, so iron losses only occur in the stator iron cores.

- In the calculation of losses due to an alternating magnetic field, only the fundamental components of the field are used. 


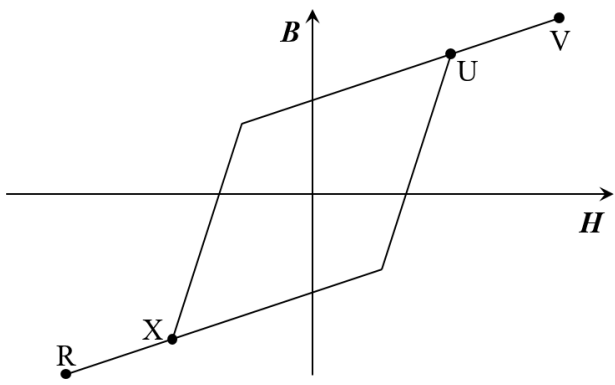

Fig. 6. Hysteresis loop of iron with heavy saturation. The area of hysteresis loop become maximum and constant when the magnetic field is above $B_{\text {hys }}$ at the point of $\mathrm{U}$ (also $\mathrm{X}$ ). The relative permeability becomes $\mu_{r}=1$ from $\mathrm{U}$ to $\mathrm{V}$ and from $\mathrm{X}$ to $\mathrm{R}$.

1) Copper losses: The copper Joule loss $P_{C u, j o u l}$ can easily be calculated. However, the calculation for the copper eddy current loss is a bit complicated since it is a function of the magnetic flux density and the fineness of stranding or transposing. Here only stranding is employed and modeled while the transposing is not. The copper eddy current loss can be expressed by [19]

$$
P_{C u, e d d y}=\frac{1}{24 \rho_{C u}} \omega^{2}\left(a^{2} \hat{B}_{r}^{2}+b^{2} \hat{B}_{t}^{2}\right) V_{C u, s}
$$

where $\omega$ is the angular electrical frequency, $\hat{B}_{r}$ and $\hat{B}_{t}$ are the radial and tangential components of the flux density (amplitude) in the copper conductor respectively, $V_{C u, s}$ is the copper volume only in the stack length, and $a$ and $b$ are the height and width of a copper strand. We assume very fine strands for the copper conductors with $a=b=1 \mathrm{~mm}$.

2) Iron losses: The eddy current loss per unit iron mass is basically calculated by [20]

$$
P_{F e, e d d y}=2 k_{e}\left(\frac{f}{50 \mathrm{~Hz}}\right)^{2}\left[\left(\frac{\hat{B}_{r}}{1.5 \mathrm{~T}}\right)^{2}+\left(\frac{\hat{B}_{t}}{1.5 \mathrm{~T}}\right)^{2}\right]
$$

where $k_{e}=0.5 \mathrm{~W} / \mathrm{kg}$ is the eddy current loss per unit iron mass with the field of $1.5 \mathrm{~T}$ and the frequency of $50 \mathrm{~Hz}, B_{r}$ and $B_{t}$ are the radial and tangential components of the flux density (amplitude) in the iron core respectively. Equation (7) applies to both the stator iron teeth and the stator iron yoke.

The hysteresis loss per unit iron mass is calculated by

$$
P_{F e, h y s}=2 k_{h}\left(\frac{f}{50 \mathrm{~Hz}}\right)\left(\frac{B_{\text {norm }}}{1.5 \mathrm{~T}}\right)^{2}
$$

where $k_{h}=2.0 \mathrm{~W} / \mathrm{kg}$ is the hysteresis loss per unit iron mass with the field of $1.5 \mathrm{~T}$ and the frequency of $50 \mathrm{~Hz}, B_{\text {norm }}$ is the norm of the flux density (peak value) in the iron core. Equation (8) applies to both the stator iron teeth and the stator iron yoke.

The factor of 2 is included in Eqs. (7) and (8) because the flux density distribution contains harmonics, which increases the iron losses. In addition, manufacturing of steel laminates into a core increases the iron losses [20]. This factor is approximated to range from 1.5 to 2.0 according to [17].

The hysteresis loss per unit volume is the area of the hysteresis loop multiplied by the frequency. When the applied magnetic field exceeds the upper field of the maximum hysteresis loop (e.g. $B_{h y s}$ ), the hysteresis loss per unit volume per electrical cycle will become constant as the area of the maximum hysteresis loop. This maximum loop implies that the hysteresis loss has an upper limit even if a higher magnetic field can be imposed on the iron.

This upper limit also leads to the fact that it is not convenient anymore to separate the field into two orthogonal components because it is hard to define the upper limit in either of the orthogonal components. By using the norm of the flux density, the upper limit can be assumed to be $B_{h y s}=2.5 \mathrm{~T}$, above which the hysteresis loss remains maximum and constant.

The total iron loss in the stator $P_{F e s}$ is therefore given by

$$
P_{F e s}=P_{F e, e d d y}+P_{F e, h y s}
$$

3) Total loss: The total loss $P_{\text {loss }}$ is obtained by adding up the three losses:

$$
P_{\text {loss }}=P_{C u, j o u l}+P_{C u, e d d y}+P_{F e s}
$$

The effects of excitation on the total loss are shown in Fig. 7 for two armature current densities and three air gap diameters. The dashed lines of $3 \%$ and $2 \%$ of the rated power of $10 \mathrm{MW}$ are also plotted to indicate two reference loss levels for an SC generator. A loss of $2 \%$ plus a cryogenic cooling power of roughly $0.5 \%$ results in a higher efficiency $(97.5 \%)$ compared to a PMDD generator (96\%) [21].

Compared to the study on the efficiency in Section III-B, the total loss here consists of not only copper Joule losses but also iron losses and copper eddy current losses. The latter two losses are functions of the frequency or the number of poles and the amplitude of magnetic fields according to Eqs. (6)-(8). As a result, a larger air gap diameter, i.e. a larger linear speed $v$, does not definitely mean a lower total loss anymore. For the case of $D_{s}=14.26 \mathrm{~m}$ as shown in Fig. 7, the total loss turns reversely to go higher when the excitation reaches a very high level, e.g. $1000 \mathrm{kAt}$ with $J_{s}=2 \mathrm{~A} / \mathrm{mm}^{2}$. This is mainly a result of a higher copper eddy current loss together with a higher iron loss due to such a high excitation and frequency. For the same diameter of $D_{s}=14.26 \mathrm{~m}$, the total loss cannot even reach the $2 \%$-loss level with $J_{s}=3 \mathrm{~A} / \mathrm{mm}^{2}$ no matter how far the excitation increases. Reducing the armature current density to $J_{s}=2 \mathrm{~A} / \mathrm{mm}^{2}$ makes it possible to achieve $2 \%$ but only in a small range of excitation. This result implies that reducing the armature current density apparently reduces the total loss while increasing the air gap diameter may not.

The topologies with more iron cores, e.g. T9-T12, reach the $2 \%$-loss level more easily than the topologies with more non-magnetic cores, e.g. T1-T4. The other topologies lie in between. At low excitation, e.g. below $200 \mathrm{kAt}$, the total loss of the topologies is considerably different. The topologies of T11 and T12, are much more efficient than the other topologies. However, the difference becomes much smaller when the excitation increases significantly, since heavy saturation makes the magnetic circuit similar for all the topologies and produces more iron losses in the topologies with iron stator cores.

\section{Generator Characteristics}

The generator characteristics, such as normal stress, stack length and active material mass, are calculated to show the 


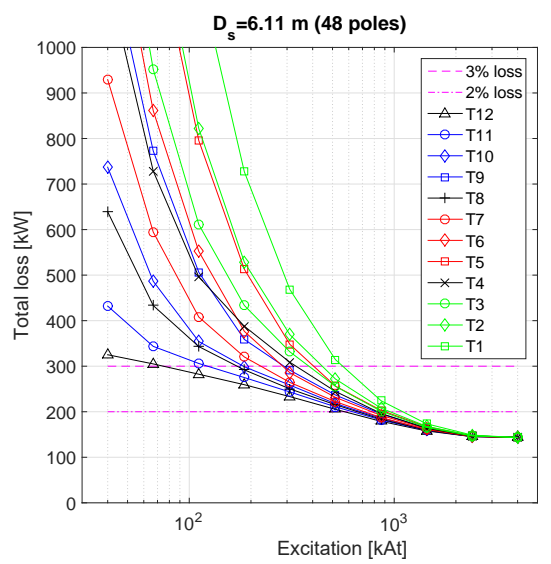

(a) $J_{s}=3 \mathrm{~A} / \mathrm{mm}^{2}, D_{s}=6.11 \mathrm{~m}$

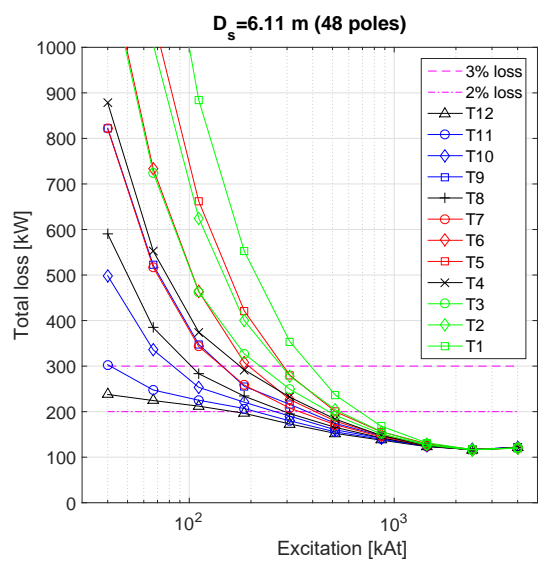

(d) $J_{s}=2 \mathrm{~A} / \mathrm{mm}^{2}, D_{s}=6.11 \mathrm{~m}$

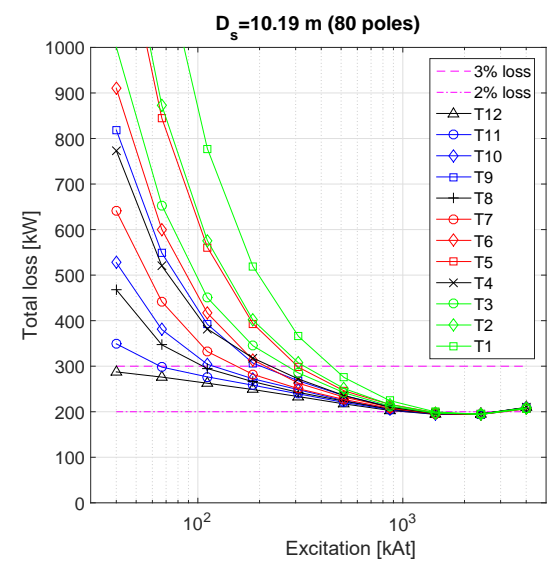

(b) $J_{s}=3 \mathrm{~A} / \mathrm{mm}^{2}, D_{s}=10.19 \mathrm{~m}$

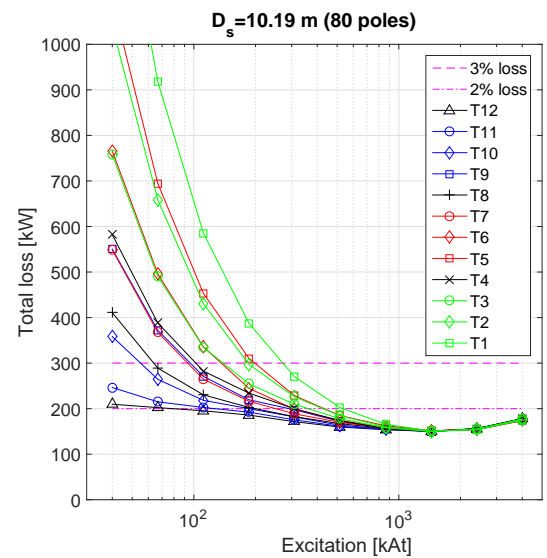

(e) $J_{s}=2 \mathrm{~A} / \mathrm{mm}^{2}, D_{s}=10.19 \mathrm{~m}$

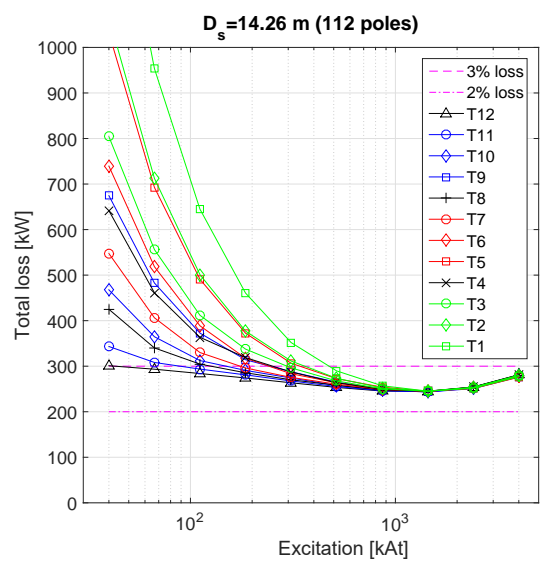

(c) $J_{s}=3 \mathrm{~A} / \mathrm{mm}^{2}, D_{s}=14.26 \mathrm{~m}$

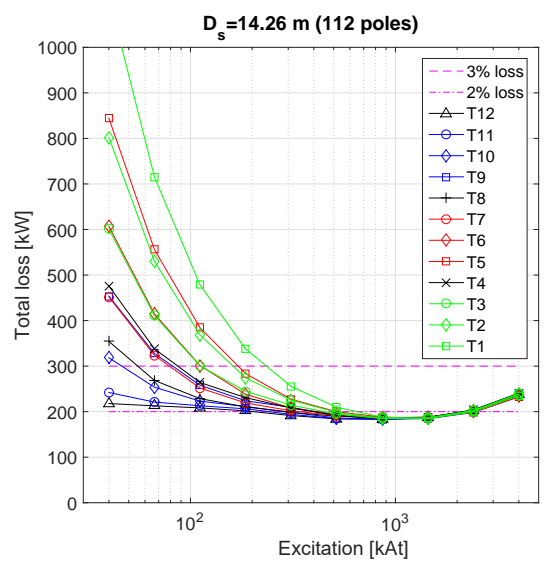

(f) $J_{s}=2 \mathrm{~A} / \mathrm{mm}^{2}, D_{s}=14.26 \mathrm{~m}$

Fig. 7. Total loss of topologies T1-T12 with respect to excitation currents for diameters of $6.11 \mathrm{~m}, 10.19 \mathrm{~m}$ and $14.26 \mathrm{~m}$ as well as current density of $J_{s}=3$ $\mathrm{A} / \mathrm{mm}^{2}$ and $J_{s}=2 \mathrm{~A} / \mathrm{mm}^{2}$. The horizontal dashed lines indicate loss levels of $2 \%$ and $3 \%$, respectively.

trend of increasing the excitation current. For calculating the normal stress, it is not needed to know the rated torque, rated speed and air gap diameter. For calculating the other generator characteristics, we use the rated torque of $T_{e}=10 \mathrm{MN} \cdot \mathrm{m}$ and the rated angular speed of $n_{N}=9.6 \mathrm{rpm}$. Two air gap diameters $D_{s}=6.11 \mathrm{~m}$ and $14.26 \mathrm{~m}$ are compared.

\section{A. Normal Stress}

The normal stress $\sigma_{r}$ indicates the attractive force between the rotor and stator and influences the structural mass which contributes to the total generator mass. Here we only estimate the normal stress at no load, because the armature load current contributes much less to the normal stress than the field current in a partially SC generator. For example, the fraction is less than $1 \%$ for the topology T12 which has the most iron in the core. This no load means that no force is produced by armature currents and the normal force is only produced between field currents and stator iron cores.

Firstly we calculate the resultant normal force on one pole $F_{r}$ with the Maxwell stress tensor by

$$
F_{r}=\frac{1}{2 \mu_{0}} \int_{l_{1}=0}^{l_{2}=\tau_{p}}\left(B_{r}^{2}-B_{t}^{2}\right) d l
$$

Although not uniformly distributed over one pole, the normal stress $\sigma_{r}$ can be calculated by averaging $F_{r}$ over one pole:

$$
\sigma_{r}=\frac{F_{r}}{\tau_{p}}
$$

The average normal stress between the rotor and stator is plotted in Fig. 8 with respect to the excitation current, assuming an unchanged air gap length. As an example, the normal stress of a PMDD machine $(200 \mathrm{kPa})$ is also indicated in both of the sub-figures for comparison [15]. The topologies with iron stator teeth (T9-T12) have higher normal stresses than the topologies with non-magnetic stator teeth (T5-T8). In the topologies with an ironless stator (T1-T4), the normal stress is $\sigma_{r}=0$.

With a higher excitation, the normal stress becomes much greater in the topologies with iron stator teeth (T9-T12) or iron stator yoke (T5-T8). These normal stresses are much higher than those of a PMDD machine. As a result, the mechanical structure must be designed to support the rotor and stator under such high normal stresses. High normal stresses will thus be a significant challenge if a higher excitation has to be used for a high shear stress and a low total loss. 


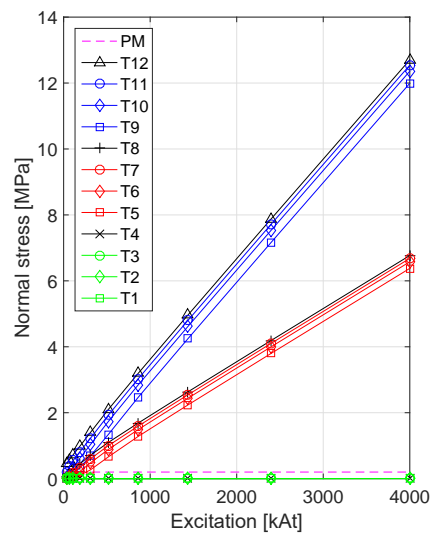

(a) Full range

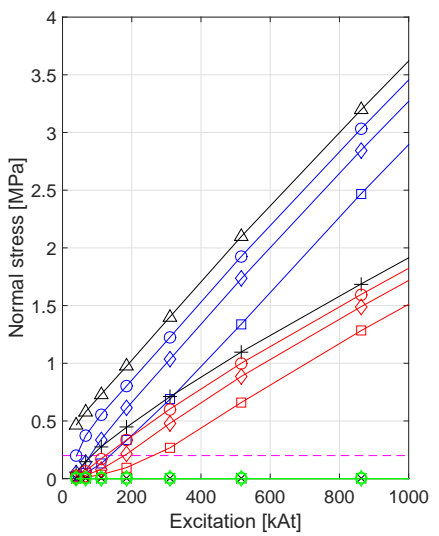

(b) Zoom in (low excitation)
Fig. 8. Average normal stress (attractive force density) per pole between the rotor and stator with respect to excitation currents. The horizontal dashes line indicates the typical level of a PMDD generator.

\section{B. Stack length}

The stack length $L_{s}$ is calculated from the sizing equation Eq. (1):

$$
L_{s}=\frac{2}{\pi} \frac{T_{e}}{\sigma_{t} D_{s}^{2}}
$$

if we set the torque to $T_{e}=10 \mathrm{MN} \cdot \mathrm{m}$ for a $10 \mathrm{MW}$ directdrive wind turbine. The results of stack length obtained with $J_{s}=3 \mathrm{~A} / \mathrm{mm}^{2}$ are shown in Fig. 9. In general, the stack length decreases when the excitation increases. The stack length of the topologies with more non-magnetic cores decreases very fast, whereas that of the topologies with more iron cores decreases slowly. However, the fact is that the topologies with more iron cores already have much smaller stack lengths at low excitation.

The reference stack length of a $10 \mathrm{MN} \cdot \mathrm{m}$ PMDD generator is also indicated by the dashed lines in this figure. This stack length is obtained by assuming a shear stress of $53 \mathrm{kPa}$. A half of this stack length is also shown for the shear stress of $106 \mathrm{kPa}$. This stack length will be achieved when the excitation is as high as $200 \mathrm{kAt}$ for T12 and $800 \mathrm{kAt}$ for T1 for both the diameters. The other topologies lie in between. The topologies with more iron require lower excitation currents.

If the excitation increases to about $4000 \mathrm{kAt}$, the difference of stack length for the topologies becomes minuscule. This vanishing difference is because the completely saturated iron behaves like a non-magnetic material, and then all the topologies have the same magnetic reluctance.

\section{Active material mass}

The active material mass consists of the core mass and the copper mass, neglecting the insignificant mass of the SC field winding. The iron mass density is $7650 \mathrm{~kg} / \mathrm{m}^{3}$ and the nonmagnetic core material (i.e. glass fiber G10) has a mass density of $1850 \mathrm{~kg} / \mathrm{m}^{3}$. The copper mass density is $8900 \mathrm{~kg} / \mathrm{m}^{3}$.

The active material mass is not fully but nearly proportional to the stack length. It thus follows a trend similar to the stack length, as shown in Fig. 10. A larger diameter reduces the active material mass, but it does not change the ranking of

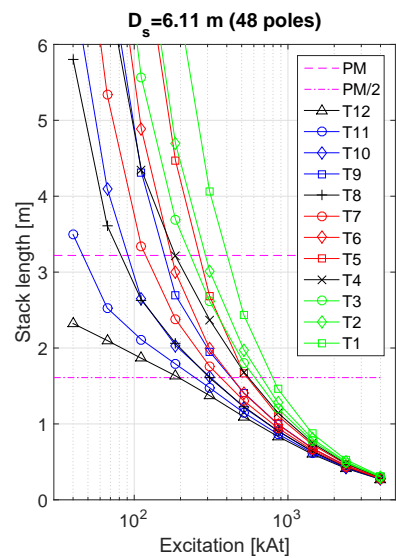

(a) $6.11 \mathrm{~m}$

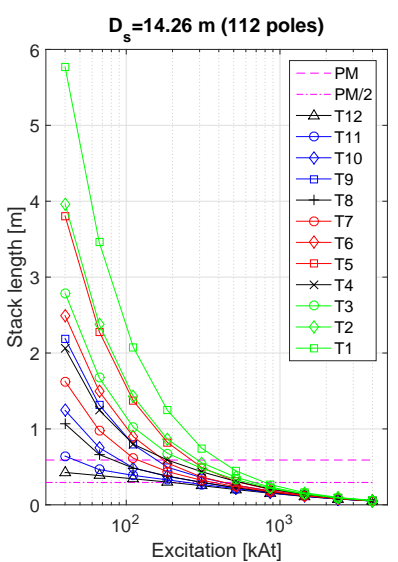

(b) $14.26 \mathrm{~m}$
Fig. 9. Stack length with respect to excitation currents for diameters of 6.11 $\mathrm{m}$ and $14.26 \mathrm{~m}$. Dashed horizontal lines indicate the typical stack length of a PMDD generator (upper) and half the PMDD generator level (lower).

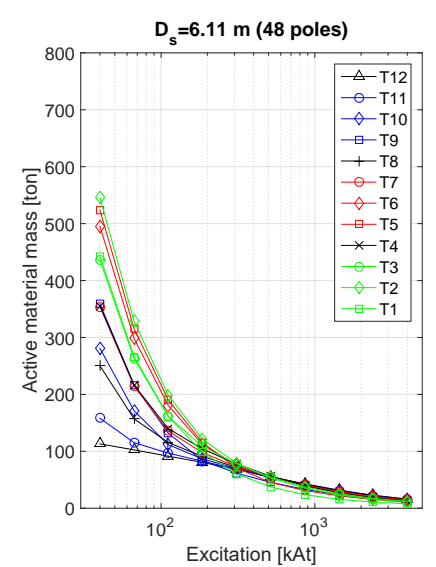

(a) $6.11 \mathrm{~m}$

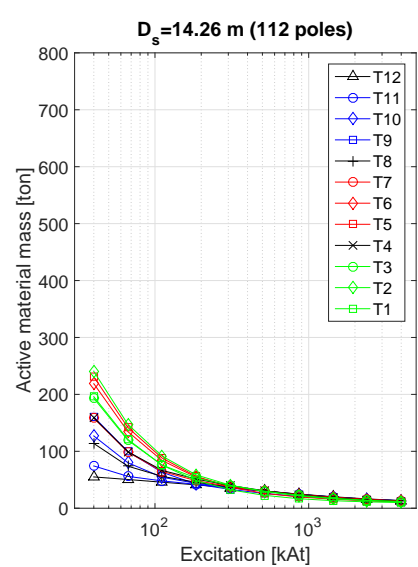

(b) $14.26 \mathrm{~m}$
Fig. 10. Active material mass with respect to excitation currents for diameters of $6.11 \mathrm{~m}$ and $14.26 \mathrm{~m}$, with $J_{s}=3 \mathrm{~A} / \mathrm{mm}^{2}$.

the compared twelve topologies. Also, with a high excitation, e.g. above $300 \mathrm{kAt}$, the difference between the active material mass of all the topologies becomes small.

With the same excitation in the region of low excitation (e.g. lower than $100 \mathrm{kAt}$ ), using iron cores can provide a lower active material mass. Using lightweight non-magnetic core materials, e.g. composites, is thus not the only choice to reduce the active material mass. For a higher excitation over $100 \mathrm{kAt}$, however, using either iron cores or non-magnetic cores with the same excitation does not make big differences.

\section{Discussion on Design Examples in Literature}

In the literature, a few designs have been proposed for partially SC generators for $10 \mathrm{MW}$ direct-drive wind turbines. Five available design examples which provide sufficient design details are summarized in Table I. They use different excitation currents (Exci.), superconductor types (SC type), cryogenic temperatures (Temp.), armature current densities $\left(J_{s}\right)$, shear stresses $\left(\sigma_{t}\right)$ and air gap diameters $\left(D_{s}\right)$, resulting in the different stack length $\left(L_{s}\right)$, active material mass $\left(M_{a c t}\right)$ and 
TABLE I

Design Examples of Partially SC Generators For 10 MW Direct-Drive Wind Turbines

\begin{tabular}{|c|c|c|c|c|c|c|c|c|c|c|c|c|}
\hline Design & Topology & $\begin{array}{l}\text { SC } \\
\text { type }\end{array}$ & $\begin{array}{l}\text { Temp. } \\
\text { (K) }\end{array}$ & $\begin{array}{l}\text { Exci. } \\
\text { (kAt) }\end{array}$ & $\begin{array}{l}J_{s} \\
\left(\mathrm{~A} / \mathrm{mm}^{2}\right)\end{array}$ & $\begin{array}{l}\sigma_{t} \\
(\mathrm{kPa})\end{array}$ & $\begin{array}{l}\tau_{p} \\
(\mathrm{~m})\end{array}$ & $\begin{array}{l}D_{s} \\
(\mathrm{~m})\end{array}$ & $\begin{array}{l}L_{s} \\
(\mathrm{~m})\end{array}$ & $\begin{array}{l}M_{a c t} \\
\text { (ton) }\end{array}$ & Efficiency & Reference \\
\hline Abrahamsen & T5 & $\mathrm{MgB}_{2}$ & 20 & 470 & 3.0 & 75 & 0.536 & 5.46 & 3.10 & 52 & $\dagger 96.7 \%$ & [9] \\
\hline Tecnalia & $\mathrm{T} 8$ & $\mathrm{MgB}_{2}$ & 20 & 230 & 3.0 & 112 & 0.660 & 10.10 & 0.74 & 118 & $\dagger+96.2 \%$ & [12] \\
\hline GE & T9 & $\mathrm{NbTi}$ & 4 & 928 & $\dagger \dagger+2.5$ & 179 & 0.379 & 4.34 & 1.88 & ${ }^{\dagger \dagger} 70$ & $95.7 \%$ & [10] \\
\hline $\mathrm{Xu}$ & $\mathrm{T} 12$ & HTS & 50 & 31 & 3.0 & †††† 109 & 0.438 & 13.40 & 0.31 & 49 & $96.8 \%$ & [11] \\
\hline Liu & $\mathrm{T} 12$ & $\mathrm{MgB}_{2}$ & 20 & 25 & 3.0 & 74 & 0.471 & 6.00 & 2.56 & 149 & $96.9 \%$ & [13] \\
\hline
\end{tabular}

$\dagger$ Estimated with the copper Joule loss of $2.3 \%$ given in [9], considering an additional copper eddy current loss of roughly $1 \%$.

†† Estimated with the parameters provided in [10].

$\dagger \dagger \dagger$ Estimated with the overall efficiency of $95.2 \%$ provided in [12], plus assumed $1 \%$ for cryogenic cooling and auxiliary components.

††† Estimated with the generator size and torque provided in [11].

rated-load efficiency (only considering copper and iron losses in the generator). Each of these designs originates from one of the twelve topologies listed in Fig. 1 and their corresponding topologies are also indicated in Table I.

- GE design employing NbTi at $4 \mathrm{~K}$ has already obtained a competitively small size ( $4.34 \mathrm{~m}$ diameter) and active material mass with a very high excitation of $928 \mathrm{kAt}$. The resulting shear stress is as high as $179 \mathrm{kPa}$. Its efficiency is only $96 \%$ and can not comply with the efficiency demand of $98 \%$. It is also observed that no further efficiency increase can be obtained by increasing the excitation. However, the efficiency could be improved by, for example, enlarging the air gap diameter or reducing the armature current density.

- Abrahamsen's and Liu's designs both have small diameters of $6 \mathrm{~m}$ but the generators are both long due to relatively low shear stresses of $75 \mathrm{kPa}$. Abrahamsen's design is lightweight because of its non-magnetic cores, but it employs the topology T5 which results in a bulky and costly SC field winding [9]. On the contrary, Liu's design using the topology T12 has heavy active materials due to a large amount of iron, but it uses much less superconductors and then could have a lower active material cost [13]. This large active material mass needs to be reduced by increasing the excitation.

- Tecnalia's and Xu's designs have higher shear stresses compared to Abrahamsen's and Liu's designs. Tecnalia's design based on the topology T8 also uses a large air gap diameter $(10.10 \mathrm{~m})$ as well as a high electrical loading $(120 \mathrm{kA} / \mathrm{m})$ to achieve its axial length $(0.74 \mathrm{~m})$ and active material mass (118 tons). Xu's design also based on the topology T12 uses an even larger air gap diameter $(13.40 \mathrm{~m})$ as well as a high electrical loading $(120 \mathrm{kA} / \mathrm{m})$ to achieve a lightweight generator design (49 tons). However, these two designs both have efficiencies below $97 \%$ and their high electrical loadings increase the complexity of cooling the armature winding.

None of the five designs in Table I provide an efficiency of over $98 \%$ (or the $2 \%$-loss level) without considering the cryogenic cooling power. Reducing the armature current density or increasing the air gap diameter together with a much higher excitation current can be considered to address this challenge.

\section{Feasibility of Commercial Superconductors}

Not all SC wires can achieve the high excitation for a shear stress of $106 \mathrm{kPa}$ and a 2\%-loss level, because the

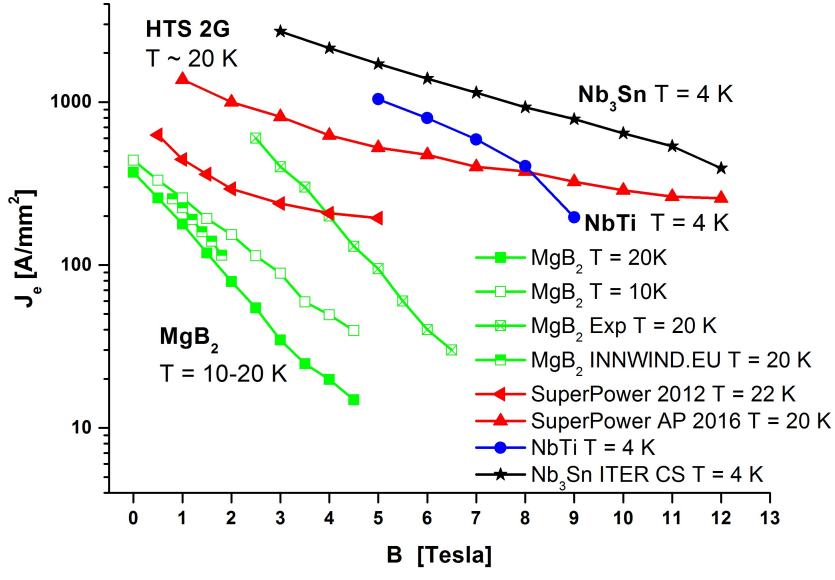

Fig. 11. Critical engineering current density $J_{e}$ of commercial superconducting wires. References: $\mathrm{NbTi}$ from [10], $\mathrm{Nb}_{3} \mathrm{Sn}$ from [22], $\mathrm{MgB}_{2}$ from [23], HTS 2G SuperPower 2012 from [24] and HTS 2G SuperPower 2016 from [25]. The base $\mathrm{MgB}_{2}$ is the production wire in 2013. $\mathrm{MgB}_{2}$ Exp is an experimental wire reported in 2013. $\mathrm{MgB}_{2}$ INNWIND.EU is from the deliverable report for the INNWIND.EU project.

current density is limited by the critical engineering current density $J_{e}$ as shown in Fig. 11 for different SC wires. When evaluating the superconductors, we need to know the magnetic flux density $B$ which the superconductors are exposed to. The magnetic flux density is produced by the excitation of SC field windings.

The four topologies (T5, T8, T9 and T12) of the five design examples shown in Table I will be used to evaluate the feasibility of superconductors.

\section{A. Required Excitation}

By comparing Fig. 4 and Fig. 7, it is seen, that it is harder to reach the $2 \%$-loss level than reaching the shear stress of $106 \mathrm{kPa}$ for $J_{s}=3 \mathrm{~A} / \mathrm{mm}^{2}$. If the armature current density is reduced to $J_{s}=2 \mathrm{~A} / \mathrm{mm}^{2}$, the $2 \%$-loss level will be fulfilled before the shear stress demand of $106 \mathrm{kPa}$ is reached. Therefore, the criteria for selecting the required excitations are to achieve the $2 \%$-loss level for $J_{s}=3 \mathrm{~A} / \mathrm{mm}^{2}$ and to achieve the shear stress of $106 \mathrm{kPa}$ for $J_{s}=2 \mathrm{~A} / \mathrm{mm}^{2}$.

Table II shows the excitations required by the four topologies. Three air gap diameters $(6.11 \mathrm{~m}, 10.19 \mathrm{~m}$ and $14.26 \mathrm{~m})$ 
TABLE II

REQUiRED EXCITATION (KAT) FOR DIFFERENT TOPOLOGIES TO ACHIEVE THE SHEAR STRESS OF 106 KPA AND THE 2\%-LOSS LEVEL

\begin{tabular}{c|rrr|rrr}
\hline \hline$J_{s}$ & \multicolumn{3}{|c|}{$\dagger 3 \mathrm{~A} / \mathrm{mm}^{2}$} & \multicolumn{3}{c}{$\dagger \dagger 2 \mathrm{~A} / \mathrm{mm}^{2}$} \\
\hline$D_{s}(\mathrm{~m})$ & 6.11 & 10.19 & 14.26 & 6.11 & 10.19 & 14.26 \\
\hline $\mathrm{T} 5$ & 910 & 1370 & $\mathrm{n} / \mathrm{a}$ & 550 & 550 & 550 \\
$\mathrm{~T} 8$ & 680 & 1250 & $\mathrm{n} / \mathrm{a}$ & 310 & 310 & 310 \\
$\mathrm{~T} 9$ & 820 & 1280 & $\mathrm{n} / \mathrm{a}$ & 450 & 450 & 450 \\
$\mathrm{~T} 12$ & 580 & 1050 & $\mathrm{n} / \mathrm{a}$ & 200 & 200 & 210 \\
\hline \hline
\end{tabular}

${ }^{\dagger}$ The loss level is just equal to $2 \%$ while $\sigma_{t}$ is higher than $106 \mathrm{kPa}$.

${ }^{\dagger \dagger} \sigma_{t}$ is just equal to $106 \mathrm{kPa}$ while the loss level is lower than $2 \%$.

and two armature current densities $\left(3 \mathrm{~A} / \mathrm{mm}^{2}\right.$ and $\left.2 \mathrm{~A} / \mathrm{mm}^{2}\right)$ are investigated. The other parameters of the generator design are identical to those used in the studies of Sections III and IV and have been described in Section II-C. For $J_{s}=3 \mathrm{~A} / \mathrm{mm}^{2}$, the required excitations are obtained when the total loss equals $2 \%$. As a result, the shear stresses with these excitations are much higher than $106 \mathrm{kPa}$. For $J_{s}=2 \mathrm{~A} / \mathrm{mm}^{2}$, the required excitations are obtained when the shear stress equals $106 \mathrm{kPa}$. As a result, the total losses with these excitations are a bit lower than $2 \%$.

As shown in Fig. 7c, none of the four topologies can achieve the $2 \%$-loss level for the air gap diameter of $D_{s}=14.26 \mathrm{~m}$ with $J_{s}=3 \mathrm{~A} / \mathrm{mm}^{2}$. For $J_{s}=3 \mathrm{~A} / \mathrm{mm}^{2}$ and $D_{s}=6.11 \mathrm{~m}$, T12 requires as high as $580 \mathrm{kAt}$ and the other topologies require even higher. Reducing $J_{s}=3 \mathrm{~A} / \mathrm{mm}^{2}$ to $J_{s}=$ $2 \mathrm{~A} / \mathrm{mm}^{2}$ makes the required excitations much lower as shown in Table II. Then, the topology T12 requires only $200 \mathrm{kAt}$ for the three diameters. With $J_{s}=2 \mathrm{~A} / \mathrm{mm}^{2}$, the three diameters of $6.11 \mathrm{~m}, 10.19 \mathrm{~m}$ and $14.26 \mathrm{~m}$ have the same required excitation for the same topology. The diameters make no difference of the require excitation so it is not needed to select a specific diameter for this evaluation of superconductors.

Also note that the required excitations listed in Table II are obtained from the design dimensioned in Section II-C for a pole pitch of $\tau_{p}=0.4 \mathrm{~m}$. This design was not optimized. Thus, the numbers of required excitations listed in Table II may not apply to other designs but are used as reference numbers.

\section{B. Resulting Magnetic Fields}

The maximum magnetic flux density in the SC coil winding produced by the required excitation is calculated in $2 \mathrm{D} \mathrm{FE}$ models. These fields depend on the cross-sectional area of the field coil. Thus, we set two realistic areas for this evaluation: $20 \times 20 \mathrm{~mm}^{2}$ and $40 \times 40 \mathrm{~mm}^{2}$. The contour of the larger field coil is sketched by the dashed boxes in Fig. 1. Figure 12 shows the maximum flux density perpendicular to the $\mathrm{SC}$ wires $B_{m p}$ and the maximum norm flux density in the $\mathrm{SC}$ wires $\left|B_{m}\right|$ as a function of excitation currents (with no armature current). The perpendicular field $B_{m p}$ is used for evaluating the SC wires which are tapes, such as HTS and $\mathrm{MgB}_{2}$. The norm field $\left|B_{m}\right|$ is used for evaluating the round $\mathrm{SC}$ wires such as $\mathrm{NbTi}$ and $\mathrm{Nb}_{3} \mathrm{Sn}$. By looking up the required excitations in Table II and the field-excitation relations in Fig. 12, the values of $B_{m p}$ and $\left|B_{m}\right|$ for the four topologies are identified and given in

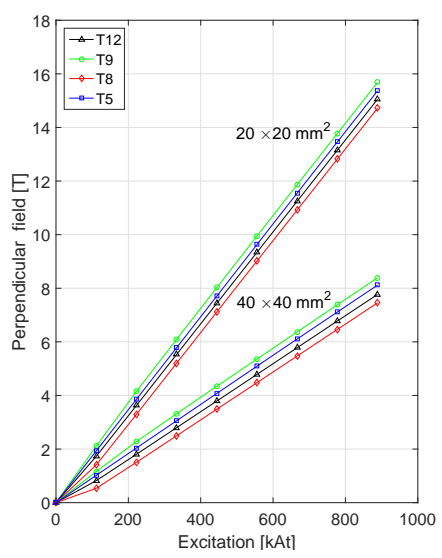

(a) Perpendicular component

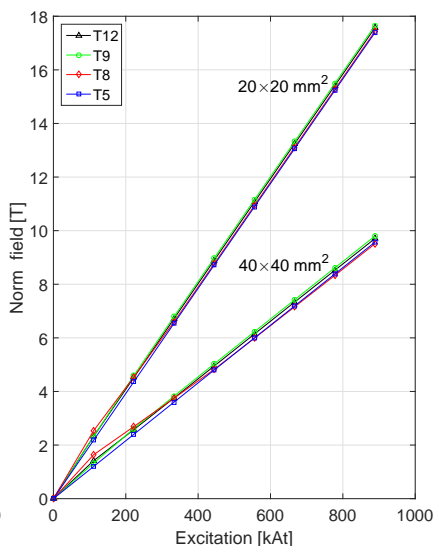

(b) Norm
Fig. 12. Maximum magnetic field at the surface of the SC field winding with respect to excitation currents for selected topologies.

Table III and Table IV. These two tables show sixteen cases (C1a, C1b ...C8a, C8b) of combining the maximum field and current density in the SC field coil.

The combination of $J_{s}=3 \mathrm{~A} / \mathrm{mm}^{2}$ and $D_{s}=6.11 \mathrm{~m}$ is a starting point. However, the maximum fields seem too high compared to Fig. 11 in most of the cases as indicated in Table III. Thus, we could use $J_{s}=2 \mathrm{~A} / \mathrm{mm}^{2}$ instead to effectively lower the maximum fields as shown in Table IV. From this point of view, $J_{s}=3 \mathrm{~A} / \mathrm{mm}^{2}$ may not be a good option. The armature current densities of the design examples in Table I could be reduced for higher generator performance. In addition, a larger cross-sectional area of the field coil produces a lower maximum field in the field coil, as indicated in Fig. 12, Table III and Table IV.

\section{Required Field Current Densities}

The required current density in the $\mathrm{SC}$ field winding $J_{f}$ is calculated by dividing the required excitation in Table II by the cross-sectional area of the field coil. The values of $J_{f}$ are shown in Table III and Table IV for the two crosssectional areas of the field coil and for $J_{s}=3 \mathrm{~A} / \mathrm{mm}^{2}$ and $J_{s}=2 \mathrm{~A} / \mathrm{mm}^{2}$, respectively. The cross-sectional area of the $\mathrm{SC}$ field coil plays an important role in determining the current density. A larger area results in a lower current density and thus a looser requirement to the superconductor. However, a larger area means a higher cost of the SC field winding.

\section{Feasible Superconductors}

To evaluate the feasibility of superconductors, we compare the sixteen cases with the critical engineering current density $J_{e}$ of the superconductors in Fig. 11. Note that $B_{m p}$ is used for HTS and $\mathrm{MgB}_{2}$ while $\left|B_{m}\right|$ is used for LTS. The feasibility of these superconductors for the sixteen cases and the four topologies is summarized in Table V.

Compared with the other SC materials, the LTS, i.e. NbTi and $\mathrm{Nb}_{3} \mathrm{Sn}$, are more feasible to achieve the shear stress of $106 \mathrm{kPa}$ and the $2 \%$-loss level for a partially SC generator. All the four topologies can employ the LTS. However, LTS 
TABLE III

Required Surface Magnetic Flux Density and Current Density for Different Topologies to Achieve the $2 \%$-Loss Level and A SHEAR STRESS OF OVER $106 \mathrm{KPA}\left(J_{s}=3 \mathrm{~A} / \mathrm{MM}^{2}, D_{s}=6.11 \mathrm{M}\right)$

\begin{tabular}{c|c|rrr|r|rrr}
\hline \hline & \multicolumn{9}{|c|}{$20 \times 20 \mathrm{~mm}^{2}$} & \multicolumn{4}{c}{$40 \times 40 \mathrm{~mm}^{2}$} \\
\hline Topology & Case & $B_{m p}(\mathrm{~T})$ & $\left|B_{m}\right|(\mathrm{T})$ & $J_{f}\left(\mathrm{~A} / \mathrm{mm}^{2}\right)$ & Case & $B_{m p}(\mathrm{~T})$ & $\left|B_{m}\right|(\mathrm{T})$ & $J_{f}\left(\mathrm{~A} / \mathrm{mm}^{2}\right)$ \\
\hline T5 & C1a & 15.7 & 17.8 & 2275 & C5a & 8.3 & 9.8 & 569 \\
T8 & C2a & 11.1 & 13.3 & 1700 & C6a & 5.6 & 7.3 & 425 \\
T9 & C3a & 14.5 & 16.3 & 2050 & C7a & 7.8 & 9.1 & 513 \\
T12 & C4a & 9.8 & 11.6 & 1450 & C8a & 5.0 & 6.4 & 363 \\
\hline \hline
\end{tabular}

TABLE IV

Required Surface Magnetic Flux Density and Current Density for Different Topologies to Achieve the Shear Stress of 106 KPa AND A LOSS LEVEL LOWER THAN $2 \%\left(J_{s}=2 \mathrm{~A} / \mathrm{MM}^{2}\right)$

\begin{tabular}{c|c|rrr|r|rrr}
\hline \hline & \multicolumn{4}{|c|}{$20 \times 20 \mathrm{~mm}^{2}$} & \multicolumn{4}{c}{$40 \times 40 \mathrm{~mm}^{2}$} \\
\hline Topology & Case & $B_{m p}(\mathrm{~T})$ & $\left|B_{m}\right|(\mathrm{T})$ & $J_{f}\left(\mathrm{~A} / \mathrm{mm}^{2}\right)$ & Case & $B_{m p}(\mathrm{~T})$ & $\left|B_{m}\right|(\mathrm{T})$ & $J_{f}\left(\mathrm{~A} / \mathrm{mm}^{2}\right)$ \\
\hline T5 & C1b & 9.5 & 10.8 & 1375 & C5b & 5.0 & 5.9 & 344 \\
T8 & C2b & 4.8 & 6.2 & 775 & C6b & 2.3 & 3.5 & 194 \\
T9 & C3b & 8.1 & 9.1 & 1125 & C7b & 4.4 & 5.1 & 281 \\
T12 & C4b & 3.2 & 4.1 & 500 & C $8 \mathrm{~b}$ & 1.6 & 2.3 & 125 \\
\hline \hline
\end{tabular}

TABLE V

FEASIBILITY OF DifFERENT SUPERCONDUCTING WIRES

\begin{tabular}{|c|c|c|}
\hline Superconductor & Feasible case & Feasible topology \\
\hline $\mathrm{MgB}_{2} 20 \mathrm{~K}$ & None & None \\
\hline $\mathrm{MgB}_{2}$ INNW. $20 \mathrm{~K}$ & None & None \\
\hline $\mathrm{MgB}_{2} 10 \mathrm{~K}$ & $\mathrm{C} 8 \mathrm{~b}$ & T12 \\
\hline $\mathrm{MgB}_{2} \operatorname{Exp} 20 \mathrm{~K}$ & $\mathrm{C} 6 \mathrm{~b}, \mathrm{C} 8 \mathrm{~b}$ & $\mathrm{~T} 8, \mathrm{~T} 12$ \\
\hline 2G HTS-2012 $22 \mathrm{~K}$ & C6b, C8b & $\mathrm{T} 8, \mathrm{~T} 12$ \\
\hline 2G HTS-2016 $20 \mathrm{~K}$ & $\begin{array}{l}\mathrm{C} 8 \mathrm{a}, \mathrm{C} 4 \mathrm{~b}, \mathrm{C} 5 \mathrm{~b} \\
\mathrm{C} 6 \mathrm{~b}, \mathrm{C} 7 \mathrm{~b}, \mathrm{C} 8 \mathrm{~b}\end{array}$ & $\begin{array}{l}\text { T5, T8, } \\
\text { T9, T12 }\end{array}$ \\
\hline NbTi $4 \mathrm{~K}$ & $\begin{array}{l}\text { C8a, C4b, C5b } \\
\text { C6b, C7b, C8b }\end{array}$ & $\begin{array}{l}\text { T5, T8, } \\
\text { T9, T12 }\end{array}$ \\
\hline $\mathrm{Nb}_{3} \mathrm{Sn} 4 \mathrm{~K}$ & $\begin{array}{l}\text { C6a, C7a, C8a, } \\
\text { C2b, C4b, C5b, } \\
\text { C6b, C7b, C8b }\end{array}$ & $\begin{array}{l}\text { T5, T8 } \\
\text { T9, T12 }\end{array}$ \\
\hline
\end{tabular}

operates at $4.2 \mathrm{~K}$ and thus requires rigorous cooling. The HTS2012 (SuperPower) is feasible for fewer cases than the LTS but the newly developed HTS-2016 (SuperPower) is comparable to the NbTi. However, they have to be cooled down to $20 \mathrm{~K}$, although they have critical temperatures of $T_{C}=93 \mathrm{~K}$. The $\mathrm{MgB}_{2}$ reported in [23] is not yet feasible for any of the four topologies at $20 \mathrm{~K}$ but feasible for $\mathrm{T} 12$ at $10 \mathrm{~K}$ with the larger field coil of $40 \times 40 \mathrm{~mm}^{2}$. A much lower temperature, such as $4 \mathrm{~K}$, could be an option but this will drastically reduce the advantage of $\mathrm{MgB}_{2}$ intended for $10-20 \mathrm{~K}$. The $\mathrm{MgB}_{2}$ used in the INNWIND.EU project seems infeasible at $20 \mathrm{~K}$ either if a realistic safety margin of current density, e.g. $20 \%$, is considered. The new lab-tested $\mathrm{MgB}_{2}$ shows its potential at $20 \mathrm{~K}$ to be feasible for T8 and T12 with the field coil of $40 \times$ $40 \mathrm{~mm}^{2}$. However, this lab-tested $\mathrm{MgB}_{2}$ is not commercially available yet.

\section{CONCLUSION}

The attractive performance of a shear stress of $106 \mathrm{kPa}$ and a 2\%-loss level can be achieved in all the twelve topologies by significantly increasing the excitation. The topologies with more iron, especially the fully iron-cored topology with salient poles, reach this performance more easily than the other topologies. Four of the twelve topologies are particularly investigated and they require excitations ranging from $200 \mathrm{kAt}$ to $550 \mathrm{kAt}$ with the armature current density of $2 \mathrm{~A} / \mathrm{mm}^{2}$. A higher armature current density, e.g. $3 \mathrm{~A} / \mathrm{mm}^{2}$, may not be a good option since it significantly increases the required excitations and challenges the superconductors.

The four topologies with such high excitations have different maximum magnetic fields in the superconducting field coil and the superconducting wires carry different current densities. By examining the critical engineering current density of commercial superconducting wires, the LTS, i.e. NbTi and $\mathrm{Nb}_{3} \mathrm{Sn}$, are capable of many of these magnetic fields and current densities at $4 \mathrm{~K}$ and thus feasible for all the four topologies. Some of the topologies may need a larger crosssectional area of the field coil. The HTS may need to be cooled down to a relatively low temperature, e.g. $20 \mathrm{~K}$, to increase its current density capability. At $20 \mathrm{~K}$, the HTS is feasible for fewer topologies than the LTS but the newly developed HTS is comparable to the NbTi. The currently available $\mathrm{MgB}_{2}$ is not feasible yet for any of the four topologies at $20 \mathrm{~K}$ but only feasible for the fully iron-cored topologies with salient poles at $10 \mathrm{~K} . \mathrm{MgB}_{2}$ superconductors, which are proposed for temperatures of $10-20 \mathrm{~K}$, need further development to carry sufficient current densities in high magnetic fields.

\section{ACKNOWLEDGMENT}

This work is part of the INNWIND.EU project supported by the FP7 framework of EU, under grant agreement No. 308974. 


\section{REFERENCES}

[1] (2016, August) INNWIND.EU official website. [Online] Available: http://www.innwind.eu/

[2] A. B. Abrahamsen, N. Mijatovic, E. Seiler, T. Zirngibl, C. Træholt, P. B. Nørgård, N. F. Pedersen, N. H. Andersen and J. Østergård, "Superconducting wind turbine generators," Supercond. Sci. and Techno., vol. 23, pp. 034019, 2010.

[3] B. B. Jensen, N. Mijatovic, and A. B. Abrahamsen, "Development of superconducting wind turbine generators," Journal of Renewable and Sustainable Energy, vol. 5, pp. 023137, 2013.

[4] H. Polinder, J. A. Ferreira, B. B. Jensen, A. B. Abrahamsen, K. Atallah, and R. a. McMahon, "Trends in wind turbine generator systems," IEEE J. Emerg. Sel. Top. Power Electron., vol. 1, pp. 174185, 2013.

[5] Ronghai Qu, Yingzhen Liu and Jin Wang, "Review of superconducting generator topologies for direct-drive wind turbines," IEEE Trans. on Appl. Supercond., vol. 23, pp. 5201108, June 2013.

[6] C. Lewis, and J. Muller, "A direct drive wind turbine HTS generator," IEEE Power Engineering Society General Meeting, pp. 1-8, 24-28 June 2007.

[7] G. Snitchler, B. Gamble, C. King, and P. Winn, "10 MW class superconductor wind turbine generators", IEEE Trans. on Appl. Supercond. vol. 21, pp. 10891092, 2011.

[8] B. Maples, M. M. Hand, and W. D. Musial, "Comparative assessment of direct drive high temperature superconducting generators in multimegawatt class wind turbines," Golden, CO: National Renewable Energy Laboratory, 2010.

[9] A. B. Abrahamsen, N. Magnusson, B. B. Jensen, D. Liu and H. Polinder "Design of an $\mathrm{MgB}_{2}$ race track coil for a wind generator pole demonstration”, J. Phys.: Conf. Ser., vol. 507, pp. 032001, 2014.

[10] Fair, R. Superconductivity for Large Scale Wind Turbines, DOE report DE-EE0005143, 2012.

[11] Y. Xu, N. Maki, L. Fellow, and M. Izumi,"Electrical design study of 10-MW salient-pole wind turbine HTS synchronous generators," IEEE Trans. on Appl. Supercond., vol. 24, pp. 1-6, Dec. 2014.

[12] I. Marino et al., "Lightweight MgB2 superconducting $10 \mathrm{MW}$ wind generator," Supercond. Sci. Technol., vol. 29, pp. 024005, Feb. 2016.

[13] Dong Liu, H. Polinder, N. Magnusson, J. Schellevis, and A. B. Abrahamsen, "Ripple field AC losses in $10 \mathrm{MW}$ wind turbine generators with a $\mathrm{MgB}_{2}$ superconducting field winding," IEEE Trans. on Appl. Supercond., vol. 26, no. 3, pp. 1-5, April 2016.

[14] Dong Liu, H. Polinder, A. B. Abrahamsen and J. A. Ferreira, "Comparison of $10 \mathrm{MW}$ superconducting generator topologies for directdrive wind turbines," IEEE International Electric Machines \& Drives Conference, Coeur D'Alene, USA, pp. 174-180, May 2015.

[15] G. Shrestha, Structural Flexibility of Large Direct Drive Generators for Wind Turbines, Ph.D. dissertation, Delft University of Technology, 2013.

[16] H. Karmaker, M. Ho, D. Kulkarni, "Comparison between different design topologies for multi-megawatt direct drive wind generators using improved second generation high temperature superconductors," IEEE Trans. on Appl. Supercond., vol. 25, pp. 1-5, June 2015.

[17] Juha Pyrhonen, Tapani Jokinen, and Valeria Hrabovcova, Design of Rotating Electrical Machines, New York: Wiley, 2009.

[18] A. K. Sawhney, A Course in Electrical Machine Design, Delhi: Dhanpat Rai \& Co., 2006.

[19] A. A. Arkadan, R. Vyas, J. G. Vaidya and M. J. Shah, "Effect of toothless stator design and core and stator conductors eddy current losses in permanent magnet generators," IEEE Trans. on Energy Conversion, vol. 7, pp. 231-237, March 1992.

[20] H. Polinder, F. F. Van Der Pijl, G. J. De Vilder, and P. J. Tavner "Comparison of direct-drive and geared generator concepts for wind turbines," IEEE Trans. Energy Convers., vol. 21, no. 3, pp. 725733 , 2006.

[21] Z. Zhang, A. Matveev, S. Øvrebø, R. Nilssen and A. Nysveen, "State of the art in generator technology for offshore wind energy conversion systems," IEEE International Electric Machines \& Drives Conference, Niagara Falls, pp. 1131-1136, May 2011.

[22] E. Seiler et al., "Hysteresis Losses and Effective $J_{c}(B)$ Scaling Law for ITER Nb3Sn Strands," IEEE Trans. on Appl. Supercond., vol. 26, no. 2, pp. 1-7, March 2016.

[23] D. Doll, et al., "The Markets that are opening for MgB2 Superconductors and Related Applications", Contribution 1M-WT-I1, 11th European Conference on Applied Superconductivity, Genova 2013.

[24] D. W. Hazelton, "2G HTS Conductors at SuperPower", Low Temperature High Field Superconductor Workshop 2012 (LTHFSWS2012), Napa, CA, USA (2012).
[25] R. Nakasakiet al., "Progress of 2G HTS Wire Development at SuperPower," Presented at Applied Superconductivity Conference, ASC 2016, 1MOr2A-03, September 4-9, 2016, Denver, CO, USA. 